\title{
A comunicação contra-hegemônica capitalismo digital: limites e contradições ${ }^{1}$
}

\author{
Counter-hegemonic communication in digital capitalism: limits and \\ contradictions
}

\author{
Rafael Bellan Rodrigues de Souza*
}

\section{RESUMO}

O artigo propõe um diagnóstico do território digital como via para analisar as possibilidades de uma ação comunicativa contra-hegemônica em seu interior. A investigação segue as trilhas do materialismo histórico e percorre a indissociabilidade entre as dimensões econômico-materiais, os elementos culturais e as práticas comunicacionais centralizadas pela internet. Assim, o texto põe em relevo as amarrações estruturais existentes entre o capitalismo e a comunicação no contexto da internet. Os resultados apontam para um reconhecimento dos limites da atuação no ambiente digital, bem como a atualidade de elaboração de um novo projeto societário.

Palavras-chave: Internet; Contrahegemonia; Materialismo Histórico; Capitalismo Digital.

\begin{abstract}
The article proposes a diagnosis of the digital territory as a way to analyze the possibilities of a counter-hegemonic communicative action within it. The investigation follows the trails of historical materialism and covers the inseparability between the economicmaterial dimensions, the cultural elements and the communicational practices centralized by the internet. Thus, the text highlights the structural ties between capitalism and communication in the context of the internet. The results point to a recognition of the limits of performance in the digital environment, as well as the timeliness of the elaboration of a new civilizing project.
\end{abstract}

Keywords: Internet; Counter-hegemony; Historical Materialism; Digital Capitalism.

\section{INTRODUÇÃO}

As formas de existência no mundo do capitalismo em fase de cooperação complexa se dão no interior de um campo digital reticular capaz de centrifugar tanto a afirmação como também a negação da ordem. O sonho de uma descentralização midiática como sinônimo de emancipação parece se perder quando ela não é produzida efetivamente pelos sujeitos sociais, mas dadas de antemão pelos conglomerados econômicos, cujo maior poder é criar os algoritmos que regem a

\footnotetext{
${ }^{1}$ Uma versão inicial deste estudo foi apresentada no $7^{\circ}$ Encontro Internacional de Política Social, em junho de 2019.

* Doutor em Ciências Sociais pela Universidade Estadual Paulista Júlio de Mesquita Filho (Unesp). Professor do Programa de Pós-Graduação em Comunicação e Territorialidades da Universidade Federal do Espírito Santo (Ufes). Endereço: Av. Fernando Ferrari, $\mathrm{n}^{\circ}$ 514, Campus de Goiabeiras, Centro de Artes, Edifício Cemuni V. CEP 29075-910, Vitória, ES. Telefone: (27) 4009-2603. Email: rafaelbellan@yahoo.com.br.
} 
espinha dorsal do mundo cibernético. Assim, mais do que uma afinidade de pouca relevância concreta, o ambiente tecnológico digital é parte constitutiva das engrenagens do capitalismo no século XXI.

É com base em um diagnóstico crítico da relação entre as tecnologias de informação e o sistema sociometabólico do capital (MÉSZÀROS, 2002), que este artigo busca analisar o território das disputas comunicativas dos sujeitos emancipatórios em seu papel de ampliação das lutas que desenvolvem. Dessa forma, de natureza teóricoconceitual, este estudo tem como objetivo realizar um exame crítico da comunicação digital, entendendo-a como polo que é produto e, ao mesmo tempo, produtor ativo do modo de produção capitalista. O horizonte de investigação está direcionado na avaliação das possibilidades efetivas dos sujeitos emancipatórios expandirem suas lutas na esfera das redes, atuando, via comunicação contra-hegemônica, nas disputas de sentido e na constituição de formas de consciência direcionadas à mudança estrutural do sistema em voga.

$\mathrm{Na}$ esteira dos estudos que exploram as dimensões econômicas, políticas e culturais da comunicação, refletindo a totalidade social como um complexo de complexos (LUKÁCS, 2013), percebe-se que é impossível entender os dilemas do campo sem considerar a dinâmica material da luta de classes, pela qual se sustenta os discursos ideológicos e as estratégias de poder hegemônicos. Assim, sem tocar o quadro geral das determinações sociais envolvidas nos fenômenos comunicacionais, torna-se impossível conhecer o terreno em que sujeitos sociais devem agir.

Colocam-se, assim, pontos para o debate. Em mirada dialética, que diagnósticos são possíveis traçar do exame do território digital, em suas potencialidades e limites? Que práxis comunicativa pode inverter as relações de poder dadas na sociedade e, nas mídias sociais? Sem uma pauta anticapitalista, é possível eliminar as relações de poder na internet? Que sistema digital queremos em uma sociedade emancipada?

Na primeira parte, o texto realiza uma investigação da comunicação digital, explorando algumas características da plataformização e algoritmização da vida social, bem como a estetização e fetichização da tecnologia por parte de pensadores e ativistas. Já na segunda parte colocam-se em exame as possibilidades de uma comunicação contra-hegemônica por parte dos lutadores sociais.

\section{DIAGNÓSTICOS SOBRE AS TECNOLOGIAS DE COMUNICAÇÃO}

O advento das redes digitais e da mudança paradigmática trazida pelas chamadas TICs (tecnologias de comunicação e informação) têm colocado para os movimentos, grupos, coletivos e agentes sociais um novo território para a ação midiática radical alternativa (DOWNING, 2002). Essa comunicação contra-hegemônica pode ser compreendida como a "[...] a mídia - em geral de pequena escala e sob muitas formas diferentes - que expressa uma visão alternativa às políticas, prioridades e perspectivas hegemônicas" (p.21). Orientadas por uma visão debitária da estratégia gramsciana de disputa dos aparelhos privados de hegemonia, muitas organizações (de perspectiva transformadora) tem atuado nessas esferas, acreditando serem capazes de inverter a direção moral e intelectual vigente e sedimentar suas lutas nas consciências dos internautas - além de organizar os ciberativistas em atividades militantes. 
Contudo, a internet, muito distante de ser neutra, torna-se uma plataforma configurada pelo sistema de reprodução sociometabólica do capital $^{2}$. Ela centrifuga a negação e a afirmação da ordem, capitaneando em uma economia da atenção as informações disponibilizadas pelos internautas, rentabilizadas no bojo das trocas mercantis fetichizadas (MARX, 2013) do capitalismo big data (FUCHS; CHANDLER, 2019). As atividades desenvolvidas em seu interior aderem a um mecanismo de lucratividade de corporações rentáveis, que se ampliam em função do tempo de vida destinado a elas. Para se ter uma ideia, as cinco empresas mais valiosas do mundo são Apple, Amazon, Microsoft, Alphabet (conglomerado Google) e Facebook, todas agentes expressivas e dominantes no setor de tecnologia e informação. A concentração midiática, que já era identificado na radiodifusão, se espraia pelo ambiente digital das redes e limita qualquer papel democratizante que ele pudesse ter (MARTINS, 2020). A virulência - correta - de militantes de esquerda com o papel dos oligopólios da mídia massiva, incrivelmente, não se manifesta com a mesma verve quando o tema é o Facebook.

Ainda é muito presente em setores dos movimentos progressistas a crença no ambiente digital como democrático em si mesmo e protegido dos conglomerados econômicos. Na esteira da avaliação de autores como Castells (2007), amplia-se uma confusão a respeito da arquitetura das redes, vista como neutras, bem como cresce uma naturalização, via senso comum dos ativistas, da internet como território livre (dada pela aparência fenomênica de possibilidades de produção de conteúdo sem limites prévios facilmente identificáveis).

Talvez a propensão a priorizar as pautas identitárias e evitar a noção de luta de classes tenha levado o ativismo de muitos movimentos sociais a uma postura de ação em pequena escala, estimulados por uma rejeição aos problemas advindo da contradição capital/trabalho. O problema, como podemos interpretar com o apoio de Harvey (2016), está no fato de que enquanto os movimentam surfam nas redes, uma classe plutocrática cada vez mais poderosa domina o mundo sem ser contestada. $\mathrm{E}$ mais, ela se apoia aos "velhos" mecanismos do poder policial e do Estado repressor, que recebe o suporte das principais ferramentas de vigilância digitais disponíveis.

A aceitação de uma visão política que se entrega à estetização da política e defesa de uma diversidade nada contrária ao individualismo exaltado pelas formas capitalistas enterra a noção de um projeto emancipatório socialista e, com esse silêncio, muitos desses novos movimentos sociais tratam o sistema do capital como o "ar que respiramos", algo naturalizado e impossível de ser modificado. A aceleração patrocinada pelo novo ritmo do circuito do capital também passa por um processo irrefletido, quase sempre enumerado como subproduto da lógica maquínica tecnocêntrica.

"As rotações demoníacas do capital revolucionam sem cessar as condições de sua valorização. Essa vertigem da aceleração comprime o tempo no momento e apaga os lugares na dilatação dos espaços" (BENSAïD, 2008, p. 25). Na crítica ontológica marxiana o capital é o agente de um totalidade que envolve não só a produção econômica, mas também a circulação e distribuição, e junto desse complexo, a reprodução social. Assim, a crítica à economia política compreende uma análise do fetichismo e da ideologia que demarcam o horizonte do pensamento social.

\footnotetext{
2 Para Mészáros (2002), o sistema do capital estrutura o funcionamento da sociedade de forma orgânica, controlando seu metabolismo, ou seja, organizando o funcionamento interno de sua dinâmica social de intercâmbio com a natureza.
} 
Nítidamente para analistas críticos, nessa elaboração universalizante das frentes de atuação do capital está uma hegemonia cultural que reforça a desigualdade estruturadora tanto da difusão quanto da criação de tecnologias de informação.

A fetichização em tempos de surgimento de uma economia impulsionada pela tecnologia digital ganha novos contornos e o fato de que são as trocas mercantis que colocam como arquiteto da rede o modo de produção capitalista não pode sair de cena em uma avaliação do novo território de relações sociais. No campo da política, o que vemos é que o capitalismo comunicativo ${ }^{3}$ em vez de levar a mais distribuições equitativas de riqueza e influência, em vez de permitir o surgimento de uma variedade mais rica de modos de vida e práticas de liberdade, leva a maioria dos povos do mundo a cederem ao espetáculo e à resignação política (DEAN, 2005). Uma ideologia tecnoutópica sedimenta-se com a ilusão de um mundo sem classes gestado pela digitalização da vida, algo que busca ocultar a mineração do resíduo em forma de dados que alavanca a lucratividade das grandes empresas do Vale do Silício. "Enquanto a narrativa cultural dominante considerar a tecnologia como a arma dos fracos e dos pobres, e não como a arma apontada aos fracos e pobres, há pouca esperança de que fenômenos como o extrativismo de dados sejam realmente levados em conta" (MOROZOV, 2018, 173).

Os algoritmos das redes sociais, por exemplo, concentram poder nas plataformas, visto que elas são agentes privados buscando lucros com a mercantilização de dados e perfis, mapeando comportamentos e escalonando o modelo de participação dos cidadãos. O exercício de poder dessas organizações privadas que regulam as trocas simbólicas e expressam modelos de conduta dá-se no controle do tráfego de informações e, sob uma falsa aparência de igualitarismo participativo, gesta uma operação de lucratividade sobre o tempo livre. Essas instituições também têm como característica a execução de atividades interconectadas de exploração do trabalho, em formato de cooperação complexa.

"Elas (plataformas) estabelecem as regras que determinam quem pode participar e sob quais condições; decidem quais tipos de comunicação são permitidas e quais não são [...]" (THOMPSOM, 2018, p. 37). As plataformas digitais atuam como esfera de alto poder de seleção, que não transparece pela sua sofisticada camuflagem, dado que não opera diretamente conteúdos comunicativos, mas permite uma circulação das informações configuradas pelos seus interesses econômicos mais imediatos. Quem controla os algoritmos, controla a rede. A automatização do comportamento humano simbolizaria a tecnologia política de cimentação das preferências estranhadas de um público sondado em suas preferências aparentes, o que intensifica uma arquitetura de rede facilitadora de dispositivos de reificação. Como decorrência dessa ação ocorre a cimentação de lógicas capitalistas no ambiente digital.

Essa esfera põe em relevo "[...] um sistema de reificações cuja consequência ideológica é que as pessoas se deixam tomar pelo estranhamento com mais facilidade, sem oferecer tanta resistência, muitas vezes até com entusiasmo [...]" (LUKÁCS, 2013, p.681). Há uma corrida incessante pelas experiências imediatas, pelo efêmero, pelo descartável, e a aceleração ofertada pela nova dimensão do

\footnotetext{
${ }^{3}$ A ideia de capitalismo comunicativo ilustra uma convergência histórica específica do capitalismo com a materialidade das redes tecnológicas de comunicação. As expansões, intensificações e interconexões das TICs impactam o capitalismo e a democracia, amalgamando os dois em uma nova formação contingente.
} 
capitalismo turbinado inverte as relações entre causa e efeito. Em um passe de mágica, foi a internet quem criou a globalização, como muitos apologistas acadêmicos, admiradores das redes, insistem em apontar. "A rapidez cria a riqueza e, para completar, a felicidade! Internet, a globalização. A tecnologia rege a orquestra” (BENSAï̀, 2008, p. 27).

Žižek (2005) resgata o legado de Lênin para pensar a política em tempos de cibercultura e racionaliza sobre o ápice do fetichismo e da reificação em um processo de virtualidade, em que símbolos e bites expandem a distorção fenomênica dos processos sociais fantasmagóricos, cada vez mais abstratos. Mas, distinto da elaboração zizekiana, longe de serem imateriais, as trocas simbólicas em território digital enredam a vida produtiva e também incidem na organização de bens materiais. A divisão real/virtual nubla a compreensão de que as tecnologias da mídia transformam-se em técnicas sociais quando inseridas nas atividades e disputas de poder e passam a dinamizar as estruturas econômicas, sociais e políticas (IANNI, 1999). O fato de a realidade aparecer como uma fantasia da subjetividade e aparentemente se descolar da materialidade da vida social encobre, via dissociação entranhada entre experiência e consciência, as contradições do sistema sociometabólico do capital em seu regime de exploração e expropriação da classe trabalhadora.

Lukács argumenta que a reificação e o estranhamento "[...] têm hoje um poder que talvez seja maior do que jamais tiveram. Contudo, eles nunca estiveram ideologicamente tão ocos, tão vazios, tão pouco entusiasmadores" (2013, p. 748). 0 filósofo húngaro aponta que está posta no âmbito social a perspectiva de "[...] um processo de libertação de longo prazo e cheio de contradições e retrocessos"(2013, p.78). Para ele, não vislumbrar esse processo seria "sinal de cegueira", mas também seria ilusão a confiança imediata no sucesso momentâneo por meio de "happenings", ou mesmo, de lacrações e hashtags bem sucedidas. A velocidade intensa do tempo dada pelo sistema do capital, que acelera a vida e as percepções, talvez precise mesmo de um freio (BENJAMIN, 1994), e os projetos emancipatórios necessitem parar a catástrofe desse trem, antes que o seu descarrilhamento, convergindo com Mészáros (2002) nos leve à barbárie universal.

Superado o êxtase em torno dos potenciais irrestritos e democratizantes da internet (que muitas vezes se confunde com noções de liberdade próximas de uma racionalidade neoliberal de um novo capitalismo includente, como em Castells, $2007 \mathrm{e}$ Anderson, Bell e Shirky, 2013), percebe-se que as relações de poder e opressão de classe adquirem novas e arrojadas técnicas de vigilância e controle na rede. Distante de uma esfera reticular livre, participativa e igualitária, vislumbra-se que a tecnologia, contraditoriamente, cristaliza a marca de sua composição de classe, cuja (i)racionalidade dirige de forma reificada as trocas simbólicas e o escopo da gestão do trabalho precário e flexível.

Há uma recusa à argumentação racional, a dissolução das totalidades nas partes, o obscurecimento da universalidade em benefício das origens, das raízes e das propriedades, a estetização despolitizante da política presidem as novas núpcias barbarás da arte e da técnica (BENSAID, 2008, p. 84).

As TICs são colaboradoras e organizadoras dessa nova paisagem do metabolismo do capital. A esfera digital é privatizada e disputada pelos atores privilegiados que a utilizam para manter sua dominação. Ela opera como território em que o poderio financeiro, a influência política e os esquemas de fortalecimento do irracionalismo de 
matiz neofascista encontram eco para ideias já bastante cimentadas no senso comum estranhado.

Examinando o mundo tecnológico atual, não é difícil chegar a uma conclusão similar: no fundo, estamos diante do nosso próprio aquário digital, repleto de peixes mortos que, milagrosamente, continuam a nadar. E fazem isso apesar dos crescentes indícios de que os sonhos utópicos, que estão por trás da concepção da internet como uma rede intrinsecamente democratizante, solapadora do poder e cosmopolita, há muito perderam seu apelo universal. A aldeia global jamais se materializou - em vez disso, acabamos em um domínio feudal, nitidamente partilhado entre as empresas de tecnologia e os serviços de inteligência (MOROzOV, 2018, p. 14-15).

Esses feudos digitais criam bolhas que se cristalizam e realimentam, de forma estranhada, versões de realidade não necessariamente sustentadas por uma leitura crítica da realidade social. A fragmentação intencional das redes gerou uma intensificação de uma política de afetos fetichizados que se espraiam com facilidade no ambiente das mídias sociais. Com uma gramática interna de produção de conteúdos pautadas pela rapidez nas interações e modelada para relações sociais superficiais e dinâmicas narcísicas de cultivo de um ego competitivo descartável, em que curtidas e compartilhamentos elucidam o sucesso da participação nessa esfera virtual, nota-se que a internet reorganiza e reflete expressões cujas matrizes já se davam na vida cotidiana estranhada.

As TICs também se tornaram engrenagens privilegiadas da fábrica do sujeito neoliberal (DARDOT; LAVAL, 2016). Isso porque ao incentivar o individualismo (cada um e seu dispositivo móvel, com seu perfil único, em smartphones utilizados como uma extensão do próprio corpo material) as plataformas digitais levam os sujeitos a se comportarem como um capital em todas as dimensões de sua vida. Sustentada por uma gramática neoliberal de liberdade de trocas mercantis com base no capitalismo financeiro turbinado em rede, todos se tornam entes privados mercantilizando suas vidas, ideias e atividades laborais em esfera reticular. Cada sujeito torna-se o microcosmo do mercado mundial. Em plataformas como o Uber o que há é a camuflagem da extração de mais-valor na responsabilização individual do homemempresa (o motorista "vendedor" de serviços de transporte).

As inúmeras atividades digitais não podem ser vistas desconectadas da produção material de mercadorias. Outra forma fetichizada bastante difundida é a ilusão de que o território digital é uma grande rede, uma ágora eletrônica virtual, cuja imaterialidade se dá em um complexo autônomo, composto por uma pseudohorizontalidade autocomunicante. Não obstante, ao olharmos o trabalho em sua globalidade, surge uma intrincada articulação entre formas distintas de trabalho operacionadas pela ampliada extração de mais-valor em nível mundial.

Sem a produção de energia, de cabos, de computadores, de celulares e de uma infinidade de produtos materiais, sem o fornecimento das matérias-primas para a produção das mercadorias, sem o lançamento de satélites ao espaço para carregar seus sinais, sem a construção de edifícios onde tudo isso é produzido e vendido, sem a produção e a condução de veículos que viabilizem sua distribuição, sem toda essa infraestrutura material, a internet não poderia ser sequer conectada (ANTUNES, 2018, p. 50). 
Mesmo a utilização de um teclado demanda atividade física, de um corpo que se locomove, consome, sua, adoece, lembra Antunes com referência ao trabalho de Ursula Huws. Desta feita, a tese do fim do trabalho é mais um mito que tenta sustentar uma ideologia de desmaterialização do real tendo com base aderir à fantasia de uma sociedade planetária pautada na força apenas da informação. Em uma perspectiva crítica ontológica, o trabalho digital e informacional são particularidades da reprodução do capital em seu processo de valorização incontrolável.

O sistema de metabolismo social do capital possui uma característica totalizante e uma capacidade ambiciosa de trazer para seu centro de atividades expansionistas os polos mais diversos da vida material. Ele subsumi o trabalho em seus imperativos de valorização, sendo organicamente mutável em uma processualidade de constante mudança das relações sociais. Mesmo uma técnica que em suas características préestabelecidas poderia ter de fato um horizonte igualitário, como as utopias cibernéticas almejavam, quando se torna parte do sistema centrífugo do capital, essas qualidades são reestruturadas em um movimento delimitador, organizado pela força desse definidor universal e orgânico de modos de vida e reprodução social.

O capital se apropria dos processos e condições existentes e os
transforma em algo perfeitamente ajustado aos requisitos de um
modo de produção capitalista. O mesmo vale para as técnicas. Ele
se apropria de antigas capacidades de cooperação (como aquelas
demonstradas na construção das pirâmides do Egito) e as combina
em uma forma organizacional adequada à reprodução de uma
classe capitalista que procura colher para si todos os ganhos de
produtividade advindos da cooperação e das crescentes
economias de escala (HARVEY, 2018, p. 119).

As lutas sociais encontram-se de frente a um problema dos mais relevantes na ação de socialização de visões de mundo alternativas e também de construção de uma consciência de classe capaz de impulsionar sujeitos históricos na construção e alternativas concretas à ordem estabelecida. Os estranhamentos potencializados pelas plataformas digitais distanciam-se do controle social e coletivo do uso das mídias para a emancipação, conforme vaticinava Enzenberger (1979), e a internet colabora na reestruturação de um novo "espírito do capitalismo" (ŽlŽEK, 2011), em que, por trás de uma pseudo-autonomia dos indivíduos, ergue-se novas estratégias de gerenciamento do mundo do trabalho, além da captura da subjetividade e corrosão do caráter (SENNET, 2009). Isso sem falar na mercantilização de dados e aceleração irrestrita do fluxo de informação. Esse último elemento, particularidade de um turbocapitalismo, têm ampliado o senso comum alienado e também dificultado o debate sobre a realidade política e econômica, cada vez mais enevoada por expressões fascistóides de uma direita renovada que se adequou com mais facilidade ao modus operandi das TICs.

A tecnologia digital da atualidade, ficou evidente, não é apenas ciência aplicada, como ainda sustentam as filosofias mais vulgares da tecnologia. Ela é, na verdade, um emaranhado confuso de geopolítica, finança global, consumismo desenfreado e acelerada apropriação corporativa dos nossos relacionamentos mais íntimos (MOROZOV, 2018, p. 7).

O Big Data, esse montante gigantesco de dados examinados automaticamente proporciona aos gigantes de plataformas como Amazon e Netflix, sondar os comportamentos das massas de usuários. Esses agentes econômicos privados podem 
sabotar a democracia, como o escândalo da Cambridge Analytica e o Facebook podem atestar. As tecnologias tem seguido uma resignada função adaptativa a ordem do capital. Com aparência democrática, de acesso livre e a possibilidade de produção colaborativa, por trás da TICs há uma cumpliciosa relação com o modus operandi das classes dominantes.

\begin{abstract}
As eleições brasileiras de 2018 mostraram o alto custo a ser cobrado de sociedades que, dependentes de plataformas digitais e pouco cientes do poder que elas exercem, relutam em pensar as redes como agentes políticos. O modelo de negócios da Big Tech funciona de tal maneira que deixa de ser relevante se as mensagens disseminadas são verdadeiras ou falsas. Tudo o que importa é se elas viralizam (ou seja, se geram números recorde de cliques e curtidas), uma vez que é pela análise de nossos cliques e curtidas, depurados em retratos sintéticos de nossa personalidade, que essas empresas produzem seus enormes lucros. Verdade é o que gera mais visualizações. Sob a ótica das plataformas digitais, as fake news são apenas as notícias mais lucrativas (MOROZOV, 2018, p.11).
\end{abstract}

As chamadas "fake news" ganharam um novo ambiente para sua repercussão e se associam a uma ampliação (em progressão geométrica) da irracionalidade. Soma-se a isso a predominante rejeição, nos imaginários sociais, de um conhecimento crítico sobre a realidade social. Esse conjunto de fatores fez com que as plataformas, ao contrário da esperança de ampliar sujeitos comunicantes, se tornassem espaço de repercussão de informações conectadas a um esvaziamento crítico que obstaculariza a militância na esfera digital. Assim, a estratégia comunicacional nesse aparelho privado de hegemonia enfrenta dificuldades concretas dadas pela estrutura econômico-corporativa das redes.

\title{
CONTRA-HEGEMONIA EM TERRITÓRIO DIGITAL
}

O conceito de hegemonia em Gramsci (2011) expressa a busca pelo consenso capitaneada por um bloco histórico dominante que exerce seu poder não apenas pelo domínio material e econômico, mas também pela direção moral e intelectual da sociedade. O objetivo da hegemonia é cimentar as ideias particulares e práticas opressoras da classe materialmente dominante no todo social. Produzindo uma aliança das forças existentes, o que lhe exige, em certa medida, aceitar certas concessões, a hegemonia pode ser entendida como o próprio exercício e manutenção do poder. Como vimos, a capilaridade desse projeto ganhou uma projeção ampliada no território digital.

As infovias de comunicação e informação arquitetam a distribuição e circulação de valores e costumes e ganham espaço entre as maiorias sociais utilizando os diversos aparelhos privados de hegemonia em relevo em um dado contexto histórico. Aliás, percebe-se que a própria internet é um locus centralizador desses aparelhos ao tornar-se a "estrada" de diversas modalidades de relações sociais.

Mas como diz Williams (1979) embora a hegemonia torne-se o próprio senso da realidade para as pessoas, sendo praticada e experimentada, ela jamais será total e eterna, colocando-se contraditoriamente espaços para a contradição em seu interior. A dinâmica complexa da hegemonia, e sua necessidade de ser constantemente renovada e recriada, coloca para as classes subalternas a missão de desafiar os sentidos produzidos pelo alto, sendo que visões de mundo opostas disputam a 
direção dada. É necessário, portanto, considerar, na análise do poder, as forças que se contrapõem à hegemonia. Williams (1979) afirma que a hegemonia

\begin{abstract}
também sofre uma resistência continuada, limitada, alterada, desafiada por pressões que não são as suas próprias pressões. Temos então de acrescentar ao conceito de hegemonia o conceito de contra-hegemonia e hegemonia alternativa, que são elementos reais e persistentes na prática (p. 115-116).
\end{abstract}

Todavia, vale tomar um cuidado redobrado para que não se desmaterialize essas noções, ressemantizando a problemática gramsciana nos jogos discursivos de base pós-modernista. Pois se a hegemonia é ético-política, não pode deixar jamais de ter seu fundamento na atividade econômica. Enfrentar a hegemonia significaria, para o filósofo sardo, enfrentar o capital. A comunicação, além de ser uma produção de representações e ideias, também ocupa papel central no próprio edifício capitalista.

\begin{abstract}
As plataformas que sustentam muitos dos serviços baseados em dados e que facilitam a produção e o acesso a eles são, ao mesmo tempo, meios de comunicação e meios de produção. $O$ fato de muitas das atividades sociais (como transações financeiras e cadastros em programas públicos) serem desenvolvidas a partir delas faz com que tais infraestruturas, que são essencialmente privadas, impactem a estruturação de nossas vidas (MARTINS, 2020, p. 194)
\end{abstract}

O papel da comunicação contra-hegemônica (WILLIAMS, 1979) no seio dos movimentos sociais e partidos de esquerda, entre outros, historicamente foi a de alterar os mapas cognitivos dos oprimidos no sentido de prepará-los para a transformação social. Isso porque, concordando com Lukács "[...] o modo como a realidade existe na cabeça e no coração dos homens cotidianos é uma das mais importantes bases de determinação imediata também de sua busca prática" (2013, p. 691). Sem esse movimento de eliminação de formas reificadas de prática social, dificilmente avança-se nas pautas emancipatórias. A internet e as redes sociais presentes hegemonicamente nos dispositivos móveis tem predominado enquanto arena das batalhas ideológicas, mas, conforme muitos agrupamentos progressistas já perceberam, com vitórias sucessivas da classe dominante. Isso porque, como apresentamos anteriormente, grandes conglomerados privados dominam as malhas do tecido digital, e esse poder no desenho das relações que se dão em sua dinâmica possui um peso ainda a ser avaliado pelo pensamento social.

\begin{abstract}
Assim, continuo convencida de que o argumento mais forte para o impacto político das novas tecnologias procede precisamente no direção oposta, isto é, na direção da pós-política. Mesmo que as comunicações em rede global forneçam ferramentas e terrenos de luta, elas tornam a mudança política mais difícil - e mais necessária do que nunca. (DEAN, 2005, p.71).
\end{abstract}

Evidente que há brechas e fissuras nesse sistema digital, mas os concretos obstáculos para a militância social nessa esfera midiática têm atado potencialidades de conscientização das classes subalternas. Os algoritmos são dirigidos por estratégias de fortalecimento do mercado do capital e a comercialização de dados em ambiente big data se oculta nas trocas simbólicas dos indivíduos que, atomizados, rendem-se às gramáticas de relações digitais virtuais delimitadas pela maquinaria digital.

"Uma subjetividade política coletiva tem de se aglutinar em torno de conceitos fundamentais sobre a constituição de um motor econômico alternativo [...]" 
(HARVEY, 2016, p. 247), pois, sem essa compreensão, o capital não pode ser colocado em xeque. Os estudos de internet na perspectiva marxista têm resgatado o debate crítico em torno do papel da internet e das tecnologias da informação para a exploração, dominação e opressão. Fuchs (2016) alerta que negligenciar o papel da luta de classes no capitalismo atual conduz a uma agenda reformista incapaz de gerar alternativas a uma internet capitalista. Ele aponta alguns conceitos do campo marxistas fundamentais para uma agenda de pesquisa sobre a internet. São eles: 1) dialética; 2) capitalismo; 3) mercadoria/“mercadorização"; 4) mais-valia, exploração, alienação, classes sociais; 5) globalização; 6) ideologia(crítica da ideologia; 7) luta de classes; 8 ) bens comuns; 9) esfera pública; 10) comunismo; 11) estética.

Com esse debate, traça-se uma cartografia do território digital e abre-se espaço para um debate da tecnologia voltado à construção, com verniz libertário e anticapitalista, de plataformas regidas por outros princípios, que ressaltem o patrimônio do comum (relacionado a uma comunicação emancipada). Nesse sentido, uma das tarefas dos movimentos sociais emancipatórios seria lutar para novas construções que reelaborem possibilidades distintas de compartilhamento igualitário concreto. Até mesmo porque devemos "[...] dar atenção especial ao modo pelo qual a liberdade de expressão e a liberdade de associação são limitadas por condições desiguais de acesso (dinheiro, educação, idade etc.) e pela dominação de grandes organizações econômicas e políticas" (FUCHS, 2016, p. 84). Nesse percurso, um amplo movimento político e social da classe trabalhadora precisa perseguir uma nova internet, mas que só é possível na dinâmica de elaboração de um novo sistema social, outro motor econômico.

A dialética da emancipação não é uma marcha inevitável rumo a um fim garantido: as aspirações e as expectativas populares são variadas, contraditórias, frequentemente divididas entre uma exigência de liberdade e uma demanda de segurança. A função específica da política consiste em articulá-la e conjuga-las por meio de um futuro histórico cujo fim continua incerto (BENSAÏD, 2008, p. 31).

Não há certezas no horizonte político, mas sem a busca por uma linha radical de combate aos estranhamentos produzidos em larga escala será, tão pouco, possível avançar.

\section{CONSIDERAÇÕES FINAIS}

A tarefa dos movimentos sociais que tentam ampliar o escopo de suas bandeiras na internet e nas redes sociais deve ser refletir radicalmente sobre as reais potencialidades desses meios para avançar uma necessária bandeira anticapitalista, bem como refletir se a melhor estratégia contra o sistema em crise é de fato povoar o terreno do inimigo. Ainda que as comunicações em rede forneçam instrumentos que podem ser usados na luta, elas tornam a mudança política mais necessária do que nunca. "Nesta medida, a política, no sentido de trabalhar para mudar as condições atuais, pode muito bem exigir uma ruptura com as fantasias que nos vinculam ao capitalismo comunicacional” (DEAN, 2005, p.71, tradução nossa).

O capital não se constrói na internet, embora o utilize tanto na produção, quanto reprodução de uma gama de mercadorias. Ações coordenadas podem desmontar 
essa arquitetura, mas dependem de uma organização com força para organizá-las e sujeitos históricos possíveis de realiza-las.

O obstáculo principal dessa ação possível e necessária da política emancipatória é o cenário de crise em que há, como aponta Carcanholo e Baruco (2009), uma ampliação da acumulação do capital via reformas neoliberais apoiada por uma hegemonia pósmodernista na cultura, na estética e nas práticas comportamentais. Essas duas conjugam-se contraditoriamente em território digital. Uma operação de desmercantilização da lógica da internet pode exigir o fenecimento desse complexo em prol de novas formas de relações sociais em dinâmicas próprias. Como advertiu Marx em muitos de seus estudos, os sujeitos dessas transformações são os trabalhadores livremente associados. A coordenação da produção material e intelectual por eles não é apenas o fim desejável de um movimento direcionado a superar o sistema sociometabólico do capital, ela também se torna a mediação desde já para novas relações sociais, capazes de operacionalizar a tecnologia a fins emancipatórios, pautados não na expansão do capital, mas no desenvolvimento das capacidades humanas.

O desafio seria cultivar, para além da dinâmica paralisante das redes digitais e sua captura do tempo livre, mediações capazes de construir outro projeto societário. $\mathrm{Na}$ linha de Mészáros (2002) não basta pleitear a derrubada do complexo orgânico das estruturas do sistema do capital, urge a necessidade de instituição de um novo metabolismo social, assim como outra forma de rede digital, adequada aos novos parâmetros civilizatórios construídos coletivamente.

Artigo recebido em 02/02/2020 e aprovado em 21/04/2020.

\section{REFERÊNCIAS}

ANDERSON, C. W.; BELL, E; SHIRKY, C. Jornalismo Pós-industrial: adaptação aos novos tempos. Revista de Jornalismo ESPM, p. 30-89, abr./jun. 2013.

ANTUNES, R. O privilégio da servidão: o novo proletariado de serviço na eradigital. São Paulo: Boitempo, 2018.

BENJAMIN, W. Magia e Técnica: arte e política: ensaios sobre literatura e história da cultura. São Paulo: Brasiliense, 1994.

BENSAIID, D. Os irredutíveis: teoremas da resistência para o tempo presente. São Paulo: Boitempo, 2008.

CARCANHOLO, M.; BARUCO, G. Pós-modernismo e neoliberalismo: duas facetas ideológico-políticas de uma pretensa nova era. Revista Lutas Sociais, n. 21 e 22, 2009.

CASTELLS, M. A sociedade em rede. São Paulo: Paz e Terra, 2007.

DARDOT, P.; LAVAL, C. A nova razão do mundo: ensaio sobre a sociedade neoliberal. São Paulo: Boitempo, 2016.

DEAN, J. Communicative Capitalism: circulation and the foreclosure of politics. Cultural Politics, v. 1, n. 1, 2005.

DOWNING, J. D.H. Mídia radical: rebeldia nas comunicações e movimentos sociais. São Paulo: Editora Senac, 2002. 
ENZENSBERGER, H. M. Elementos para uma teoria dos meios de comunicação. Rio de Janeiro: Tempo Brasileiro, 1979.

FUCHS, C.; CHANDLER, D. Digital Objects. Digital Subjects. Interdisciplinary perspectives on capitalismo, labour and politics in the age of Big Data. UK: University Westminster Press, 2019.

FUCHS, C. Em direção a uma problemática marxista de estudos sobre a internet. Crítica Marxista, n. 43, p.67-93, 2016.

HARVEY, D. A loucura da razão econômica. São Paulo: Boitempo, 2018.

HARVEY, D. 17 contradições e o fim do capitalismo. São Paulo: Boitempo, 2016.

IANNI, O. O Príncipe Eletrônico. Perspectivas, São Paulo, 1999.

LUKÁCS, G. Para uma ontologia do ser social II. São Paulo: Boitempo Editorial, 2013.

MARX, K. O capital: crítica da Economia Política. Livro I. São Paulo: Boitempo, 2013.

MARTINS, Helena. Comunicações em tempos de crise. São Paulo: Expressão Popular, Fundação Rosa Luxemburgo, 2020.

MÉSZÁROS, I. Para além do capital. São Paulo: Boitempo, 2002.

MOROZOV, Evgeny. Big Tech: a ascensão dos dados e a morte da política. São Paulo: Ubu Editora, 2018.

SENNET, R. A corrosão do caráter. São Paulo: Editora Record, 2009.

THOMPSON, J. B. A interação mediada na era digital. Revista Matrizes, USP,v.12, n.3, set/dez, 2018.

WILLIAMS, R. Marxismo e Literatura. Rio de Janeiro: Zahar, 1979.

ŽlŽEK, S. Às portas da revolução: escritos de Lenin de 1917. São Paulo: Boitempo, 2005.

ŽlŽEK, S. Primeiro como tragédia, depois como farsa. São Paulo: Boitempo, 2011. 